PAPER

\title{
Sudden cardiac death in diabetes mellitus: risk factors in the Rochester diabetic neuropathy study
}

\author{
G A Suarez, V M Clark, J E Norell, T E Kottke, M J Callahan, P C O'Brien, P A Low, P J Dyck
}

J Neurol Neurosurg Psychiatry 2005;76:240-245. doi: 10.1136/jnnp.2004.039339

See end of article for authors' affiliations

.....................

Correspondence to: Dr Guillermo A Suarez, Mayo Clinic College of Medicine, 200 First Street $\mathrm{SW}$, Rochester, MN 55905, USA; suarez. guillermo@mayo.edu

Received 13February 2004 In revised form 14 May 2004 Accepted 25 May 2004

\begin{abstract}
Objectives: To determine risk factors for sudden cardiac death and the role of diabetic autonomic neuropathy (DAN) in the Rochester diabetic neuropathy study (RDNS)

Methods: Associations between diabetic and cardiovascular complications, including DAN, and the risk of sudden cardiac death were studied among 462 diabetic patients (151 type 1) enrolled in the RDNS. Medical records, death certificates, and necropsy reports were assessed for causes of sudden cardiac death.

Results: 21 cases of sudden cardiac death were identified over 15 years of follow up. In bivariate analysis of risk covariates, the following were significant: ECG 1 (evolving and previous myocardial infarctions): hazard ratio $(H R)=4.4$ (95\% confidence interval $(C I), 1.6$ to 12.1), $p=0.004$; ECG 2 (bundle branch block or pacing): $\mathrm{HR}=8.6$ (2.9 to 25.4), $\mathrm{p}<0.001$; $E C G 1$ or $E C G$ 2: $H R=4.2$ (1.3 to 13.4), $p=0.014$; and nephropathy stage: $H R=2.1$ (1.3 to 3.4), $p=0.002$. Adjusting for $E C G 1$ or ECG 2, autonomic scores, QTc interval, high density lipoprotein (HDL) cholesterol, 24 hour microalbuminuria, and 24 hour total proteinuria were significant. However, adjusting for nephropathy, none of the autonomic indices, QTc interval, HDL cholesterol, microalbuminuria, or total proteinuria was significant. At necropsy, all patients with sudden cardiac death had coronary artery or myocardial disease.

Conclusions: Sudden cardiac death was correlated with atherosclerotic heart disease and nephropathy, and to a lesser degree with DAN and HDL cholesterol. Although DAN is associated with sudden cardiac death, it is unlikely to be its primary cause.
\end{abstract}

the community, abnormality was identified from population based norms, and both univariate and multivariate analyses were undertaken, which included many risk factors.

Here we evaluate the risk factors for sudden cardiac death in the prospective, population based, Rochester diabetic neuropathy study (RDNS) cohort, by life table analysis of DAN and other risk factors on the outcome of sudden cardiac death; and by analysis of medical records, death certificates, ECG tracings, and available necropsy reports of all cases of sudden cardiac death, looking for additional evidence related to the cause of the death.

\section{METHODS}

\section{The RDNS cohort}

The RDNS is a cross sectional and longitudinal study of all consenting diabetic patients from Rochester, Minnesota (later from Olmsted County, Minnesota) initiated on 1 January 1986, enrolling 502 patients, of whom 462 (151 with type 1 diabetes) provided data for the present study. ${ }^{78}$ These patients are mainly of northern European extraction. The database from the RDNS has been used to develop and assess neuropathy tests, composite scores, and a staging approach, ${ }^{9}$ the prevalence of diabetic complications, ${ }^{8}$ progression, ${ }^{10}$ and risk factors. ${ }^{11}$

\section{The RDNS healthy subjects study (RDNS-HS)}

To develop normative test results (as centiles and normal deviate $(z)$ scores) a large cohort of randomly selected volunteers from Rochester, Minnesota was recruited and examined, excluding persons with neurological disease and

Abbreviations: CASS, composite autonomic severity scale; DAN, diabetic autonomic neuropathy; NIS, neuropathy impairment score; NSC, neuropathy symptoms and change score; QSART, quantitative sudomotor axon reflex test; RDNS, Rochester diabetic neuropathy study
In the prospective studies reported here, consenting

diabetic patients were representative of diabetic patients in
300000 to 400000 deaths annually. Sudden cardiac death employing normal test values corrected for age, sex, and cohort of healthy subjects drawn from the same populati Finally, factors other than autonomic neuropathy (for example, cardiac and kidney disease) were insufficiently taken into account in multivariate analysis. 


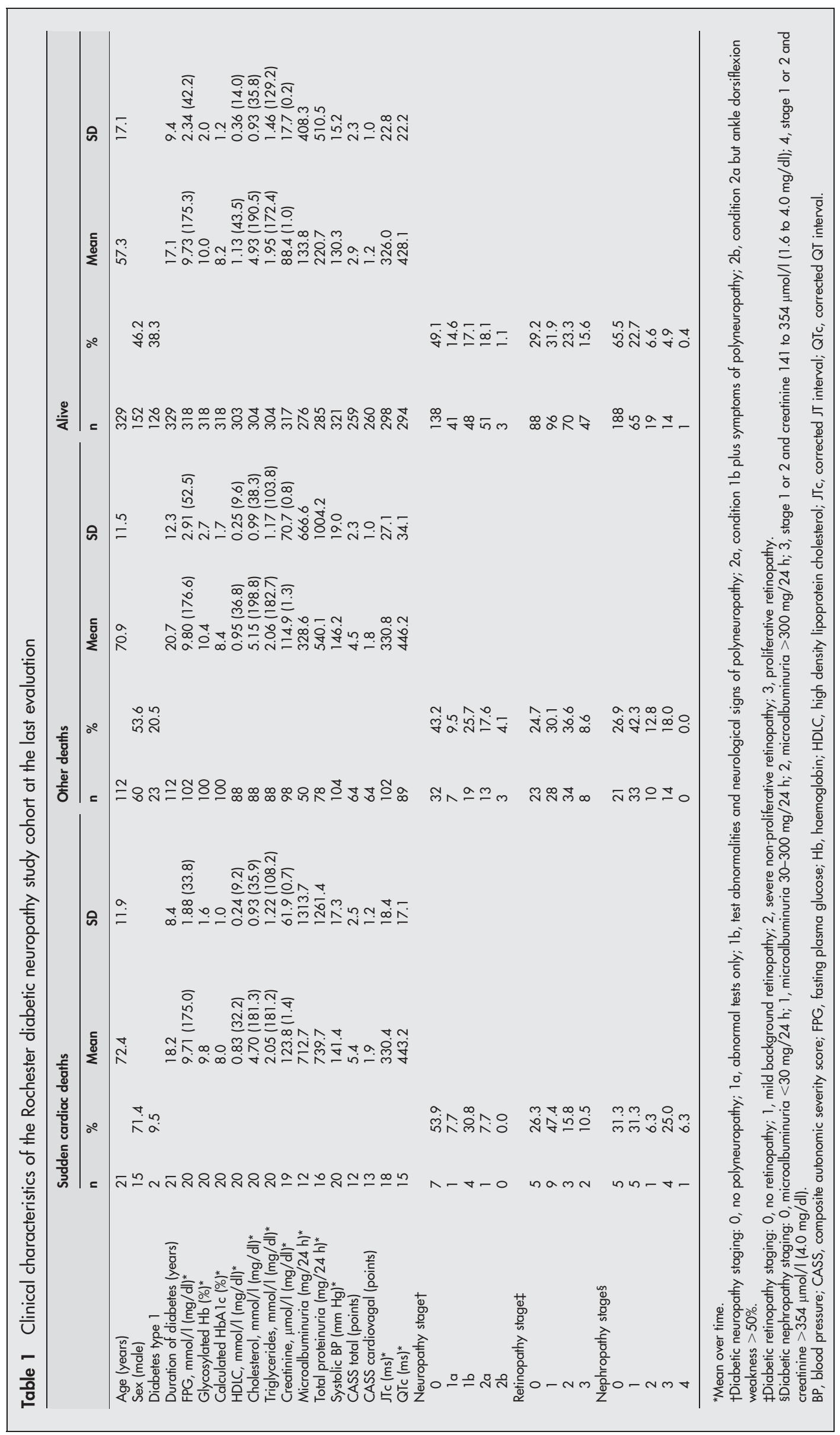


diseases predisposing to neuropathy. The test results from these healthy persons were used to estimate normative test results for quantitative sensation tests, attributes of nerve conduction, and quantitative autonomic tests, taking into account the influence of age, sex, and other applicable anthropomorphic characteristics. ${ }^{12}{ }^{13}$

\section{Assessment of neuropathy}

Assessing for the presence of neuropathy and its severity was done by prospective evaluation of the symptoms, neuropathic impairments, and test results from the patients. Neuropathic deficits were assessed by the neuropathy impairment score (NIS) and symptoms by the neuropathy symptoms and change score (NSC). The neuropathic tests assessed were nerve conduction studies, quantitative sensation, and quantitative autonomic function tests. Criteria for the diagnosis and staged severity of diabetic sensory polyneuropathy have been published..$^{14}$

\section{Assessment of autonomic neuropathy}

In addition to the history and examination, validated, standardised, quantitative autonomic studies of known sensitivity, specificity, and reproducibility were carried out on the patients to evaluate the distribution and severity of sudomotor, cardiovagal, and adrenergic impairment. Postganglionic sudomotor function was evaluated with a quantitative sudomotor axon reflex test (QSART) recorded from the forearm and three lower extremity sites. Heart rate variability to deep breathing and to the Valsalva manoeuvre was used to evaluate cardiovagal function. Adrenergic function was evaluated using the beat to beat blood pressure responses during tilt and the Valsalva manoeuvre.

The composite autonomic severity scale (CASS) is a 10 point score of autonomic function derived from the three sets of autonomic function tests (sudomotor, cardiovagal, and adrenergic). The scale rates adrenergic deficits by one of four grades, and sudomotor and cardiovagal deficits each by one of three grades. This score of autonomic failure ranges from a value of 0 (normal) to 10 (maximum deficit). Each score is normalised for the effects of age and sex. ${ }^{16}$ The procedures and methods of analysis of autonomic tests have been reported previously. ${ }^{17}$

\section{Assessment of metabolic control, diabetic complications, and putative risk factors}

Patients in the RDNS cohort underwent measurement of height, weight, body surface area, body mass index (BMI), abdominal to pelvic girth, blood pressure, heart rate, fasting plasma glucose, glycosylated haemoglobin, and calculated $\mathrm{HbA}_{\mathrm{lc}}$ every three months. Total cholesterol, high density lipoprotein (HDL) cholesterol, triglycerides, and lipoproteins were evaluated every six months. Retinopathy was assessed on seven standard retinal photographs of each eye by the Retinal Eye Reading Center, Madison, Wisconsin (Dr R Klein). Nephropathy was assessed every 12 months by measurement of 24 hour proteinuria, 24 hour microalbuminuria, and plasma creatinine. Other putative risk factors measured over time in the cohort included energy expenditure, alcohol consumption (g/week), smoking (pack-years), and other variables.

Staging of retinopathy, polyneuropathy, and nephropathy are described in table 1 and have been published. ${ }^{14}$

\section{Characterisation of ECG abnormality}

A 12-lead ECG was recorded on RDNS participants every two years. The test was also carried out at other times depending on clinical necessity, and stored as digital data on the Marquette MUSE system. In all, 8155 ECGs were available for analysis. These electronic records were analysed using a computer program that characterised each record as:

- ECG 1: consistent with evolving myocardial infarction or previous Q wave changes indicative of myocardial infarction;

- ECG 2: left bundle branch block or electronic pacing;

- other patterns.

We also analysed the QT interval and JT interval corrected for heart rate. The QTC and JTc were measured according to the following formulae:

QTc $=$ [QT wave duration $] / \sqrt{[60 / \text { ventricular rate }] ;}$

JTc $=[\mathrm{QT}$ wave duration $-\mathrm{R}$ wave duration $] /$ $\sqrt{[60 / \text { ventricular rate }] \text {. }}$

A QTc interval was not calculated if the ECG was paced or showed a left bundle branch block. A JTc interval was not calculated if the ECG was paced. This computer program has been validated by comparison with interpretation by experts in the Minnesota ECG Coding Laboratory at the University of Minnesota. ${ }^{18}$

\section{Review of death certificates, medical history, and necropsy reports}

The medical records, death certificates, and necropsy reports of all deaths in both RDNS cohorts were reviewed. Deaths were categorised as cardiac and non-cardiac. A cardiologist (TEK) categorised the cardiac deaths as sudden or nonsudden. Sudden death was defined as follows: the individual was found dead or died within one hour of symptom onset; or the individual was resuscitated from a cardiac arrest but died during the same hospital admission. The necropsy records were reviewed for the degree of coronary atherosclerosis, degree of myocardial damage, and left ventricular failure.

\section{Statistical analysis}

Life table methods were used to evaluate associations between potential risk factors and sudden cardiac death using Cox regression analysis (SAS software, version 8). Because of the small number of sudden cardiac deaths, bivariate analysis was used. Extreme caution was exercised when analysing time dependent covariates. ${ }^{19}$ Subjects who died a non-sudden cardiac death were censored at time of death. Three versions of each continuous risk factor (such as fasting plasma glucose) were considered for the analysesthe value at baseline and two time dependent variables. The time dependent variables were continuously updated during follow up. At each time (t) during follow up, we computed the variable at $t$ (current value) and the mean from baseline to $t$ (mean over time). To illustrate this, for analyses associated with a sudden cardiac death at three years, the "current value" of fasting plasma glucose entered into the analysis at that time point for all subjects would be the most recent fasting plasma glucose at three years. For stage of neuropathy, retinopathy, nephropathy, ECG 1 and ECG 2, and the autonomic tests, only the values at baseline and at time $t$ were used.

\section{RESULTS}

\section{Disease characteristics}

At analysis, death had occurred in $133(29 \%)$ of persons in the RDNS cohort and in 18 (4\%) of persons in the RDNS-HS cohort. Deaths from non-cardiac causes (cancer, vehicle accidents, and so on) occurred in 81 RDNS and 12 RDNS-HS. Of the 462 RDNS patients, 21 died suddenly, 112 died from other causes, and 329 were still alive. Of the 21 subjects who 
Table 2 Univariate risk factors for sudden cardiac death (life table analysis): RDNS sudden cardiac deaths $(n=21) v$ all other deaths + alive $(n=441)$

\begin{tabular}{|c|c|c|c|}
\hline Risk factor & HR & $95 \% \mathrm{Cl}$ & p Value \\
\hline Age ( 10 years), at last evaluation & 2.20 & 1.36 to 3.56 & 0.001 \\
\hline Type of diabetes mellitus & 4.54 & 1.06 to 19.52 & 0.042 \\
\hline Renal disease, at last evaluation & 1.64 & 0.64 to 4.25 & 0.306 \\
\hline FPG $(10 \mathrm{mg} / \mathrm{dl}(0.56 \mathrm{mmol} / \mathrm{l}))^{*}$ & 1.01 & 0.92 to 1.11 & 0.822 \\
\hline Glycosylated $\mathrm{Hb}(10 \%)^{*}$ & 0.96 & 0.77 to 1.20 & 0.717 \\
\hline Calculated $\mathrm{HbAlc}(10 \%)^{*}$ & 0.94 & 0.66 to 1.34 & 0.717 \\
\hline $\mathrm{HDLC}(10 \mathrm{mg} / \mathrm{dl}(0.26 \mathrm{mmol} / \mathrm{l}))^{*}$ & 0.50 & 0.29 to 0.87 & 0.014 \\
\hline Cholesterol $(10 \mathrm{mg} / \mathrm{dl}(0.26 \mathrm{mmol} / \mathrm{l}))^{*}$ & 0.95 & 0.82 to 1.09 & 0.434 \\
\hline Triglycerides $(10 \mathrm{mg} / \mathrm{dl}(0.11 \mathrm{mmol} / \mathrm{l}))^{*}$ & 1.01 & 0.98 to 1.05 & 0.362 \\
\hline Creatinine $(\mathrm{mg} / \mathrm{dl})^{*}$ & 1.88 & 1.33 to 2.65 & $<0.001$ \\
\hline Microalbuminuria (1000 mg/24 h)* & 2.38 & 1.50 to 3.76 & $<0.001$ \\
\hline Total proteinuria $(1000 \mathrm{mg} / 24 \mathrm{~h})^{*}$ & 1.69 & 1.24 to 2.30 & $<0.001$ \\
\hline Systolic blood pressure $(10 \mathrm{~mm} \mathrm{Hg})^{*}$ & 1.35 & 1.00 to 1.82 & 0.047 \\
\hline Smoking (10 pack years), at last evaluation & 1.17 & 0.97 to 1.39 & 0.094 \\
\hline Calcification of vessels in foot, at last evaluation & 6.73 & 1.23 to 36.86 & 0.028 \\
\hline $\mathrm{ECG} 1^{*} \dagger$ & 6.27 & 2.23 to 17.62 & 0.001 \\
\hline $\mathrm{ECG} 2^{*} \dagger$ & 7.47 & 2.43 to 22.99 & $<0.001$ \\
\hline ECG 1 or $2^{*}$ & 10.59 & 4.06 to 27.64 & $<0.001$ \\
\hline $\mathrm{JTc}(\mathrm{ms})^{*}$ & 1.01 & 0.99 to 1.03 & 0.589 \\
\hline QTc $(\mathrm{ms})^{*}$ & 1.02 & 1.01 to 1.04 & 0.005 \\
\hline CASS total (points)* & 1.52 & 1.20 to 1.91 & $<0.001$ \\
\hline CASS adrenergic (points)* & 2.06 & 1.06 to 4.00 & 0.032 \\
\hline CASS sudomotor (points)* & 1.10 & 0.39 to 3.11 & 0.860 \\
\hline CASS cardiovagal (points) & 2.50 & 1.37 to 4.55 & 0.003 \\
\hline Nephropathy stage* & 2.76 & 1.60 to 4.76 & $<0.001$ \\
\hline Neuropathy stage* & 0.84 & 0.44 to 1.59 & 0.589 \\
\hline \multicolumn{4}{|c|}{$\begin{array}{l}\text { *Mean over time. } \\
\text { †ECG 1, ECG diagnostic of acute myocardial infarction or evolving diagnostic; ECG 2, ECG with left bundle } \\
\text { branch block or electronically paced complexes. } \\
\text { Significant values in bold. } \\
\text { CASS, composite autonomic severity score; Cl, confidence interval; HDLC, high density lipoprotein cholesterol; H } \\
\text { hazard ratio; JTc, corrected JT interval; QTc, corrected QT interval; RDNS, Rochester diabetic neuropathy stud }\end{array}$} \\
\hline
\end{tabular}

died suddenly, one was successfully defibrillated and resuscitated but remained unresponsive for four days until life support measures were discontinued. Unsuccessful resuscitation attempts were documented for nine patients, and no resuscitation attempts were documented for 11 .

The age, sex, disease, and diabetic complications of the three groups of patients in the RDNS are shown in table 1.
Statistical significance is not shown because the average values are provided for descriptive purposes only and not for hypothesis testing. At the time of death or at the last examination, the group who died was older. Mean fasting plasma glucose and mean glycosylated haemoglobin were similar among the three groups. The plasma creatinine was slightly higher in the two groups who had died. There were

Table 3 Multivariate life table analysis: RDNS sudden cardiac deaths $(n=21) v$ all other deaths + alive $(n=441)$

\begin{tabular}{|c|c|c|c|c|c|c|c|c|c|}
\hline \multirow[b]{2}{*}{ Risk factor } & \multicolumn{3}{|c|}{ Adjusted for ECG $1 \dagger$} & \multicolumn{3}{|c|}{ Adjusted for ECG $2 \dagger$} & \multicolumn{3}{|c|}{ Adjusted for nephropathy stage } \\
\hline & HR & $95 \% \mathrm{Cl}$ & p Value & HR & $95 \% \mathrm{Cl}$ & p Value & HR & $95 \% \mathrm{Cl}$ & p Value \\
\hline ECG 1 & - & - & - & 4.41 & 1.60 to 12.16 & 0.004 & 2.13 & 0.63 to 7.24 & 0.224 \\
\hline ECG 2 & 8.64 & 2.94 to 25.44 & $<0.001$ & - & - & - & 5.30 & 1.35 to 20.77 & 0.017 \\
\hline ECG 1 or 2 & - & - & - & - & - & - & 4.25 & 1.35 to 13.41 & 0.014 \\
\hline $\operatorname{JTc}(\mathrm{ms})^{*}$ & 1.01 & 0.99 to 1.02 & 0.583 & 1.01 & 0.99 to 1.03 & 0.515 & 1.00 & 0.97 to 1.02 & 0.840 \\
\hline QTc $(m s)^{*}$ & 1.02 & 1.00 to 1.03 & 0.019 & 1.02 & 1.01 to 1.04 & 0.008 & 1.01 & 0.99 to 1.04 & 0.244 \\
\hline FPG $(10 \mathrm{mg} / \mathrm{dl}(0.56 \mathrm{mmol} / \mathrm{l}))^{*}$ & 1.01 & 0.92 to 1.11 & 0.803 & 1.01 & 0.92 to 1.11 & 0.765 & 1.00 & 0.89 to 1.12 & 0.986 \\
\hline Glycosylated $\mathrm{Hb}(10 \%)^{*}$ & 0.69 & 0.07 to 6.92 & 0.750 & 0.51 & 0.05 to 5.35 & 0.575 & 0.46 & 0.03 to 6.95 & 0.576 \\
\hline Calculated $\mathrm{HbAlc}(10 \%)^{*}$ & 0.55 & 0.01 to 21.56 & 0.750 & 0.34 & 0.01 to 14.32 & 0.575 & 0.29 & 0.00 to 21.69 & 0.576 \\
\hline $\mathrm{HDLC}(10 \mathrm{mg} / \mathrm{dl}(0.26 \mathrm{mmol} / \mathrm{l}))^{*}$ & 0.53 & 0.30 to 0.94 & 0.028 & 0.52 & 0.30 to 0.91 & 0.022 & 0.56 & 0.30 to 1.04 & 0.068 \\
\hline Cholesterol $(10 \mathrm{mg} / \mathrm{dl}(0.26 \mathrm{mmol} / \mathrm{l}))^{*}$ & 0.92 & 0.80 to 1.07 & 0.275 & 0.92 & 0.80 to 1.06 & 0.243 & 0.93 & 0.79 to 1.09 & 0.365 \\
\hline Triglycerides $(10 \mathrm{mg} / \mathrm{dl}(0.11 \mathrm{mmol} / \mathrm{l}))^{*}$ & 1.01 & 0.98 to 1.05 & 0.485 & 1.02 & 0.98 to 1.05 & 0.383 & 0.99 & 0.93 to 1.05 & 0.707 \\
\hline Creatinine $(\mathrm{mg} / \mathrm{dl})^{*}$ & 1.91 & 1.34 to 2.73 & $<0.001$ & 1.47 & 1.00 to 2.15 & 0.051 & 1.65 & 0.88 to 3.08 & 0.117 \\
\hline Microalbuminuria (1000 mg/24 h)* & 2.18 & 1.33 to 3.57 & 0.002 & 2.37 & 1.47 to 3.80 & $<0.001$ & 2.15 & 0.96 to 4.83 & 0.062 \\
\hline Total proteinuria $(1000 \mathrm{mg} / 24 \mathrm{~h})^{*}$ & 1.65 & 1.19 to 2.28 & 0.003 & 1.68 & 1.21 to 2.34 & 0.002 & 1.22 & 0.73 to 2.03 & 0.439 \\
\hline Systolic blood pressure $(10 \mathrm{~mm} \mathrm{Hg})^{*}$ & 1.31 & 0.97 to 1.78 & 0.080 & 1.31 & 0.97 to 1.79 & 0.080 & 1.32 & 0.89 to 1.94 & 0.165 \\
\hline CASS total (points) & 1.47 & 1.18 to 1.83 & $<0.001$ & 1.43 & 1.15 to 1.78 & 0.001 & 1.19 & 0.91 to 1.56 & 0.210 \\
\hline CASS adrenergic (points) & 2.05 & 1.26 to 3.33 & 0.004 & 1.92 & 1.20 to 3.06 & 0.006 & 1.27 & 0.65 to 2.47 & 0.481 \\
\hline CASS sudomotor (points) & 1.04 & 0.50 to 2.19 & 0.911 & 0.90 & 0.42 to 1.90 & 0.772 & 0.66 & 0.27 to 1.60 & 0.360 \\
\hline CASS cardiovagal (points) & 2.09 & 1.26 to 3.47 & 0.004 & 2.03 & 1.23 to 3.35 & 0.006 & 1.49 & 0.82 to 2.72 & 0.189 \\
\hline Nephropathy stage & 2.12 & 1.32 to 3.41 & 0.002 & 2.06 & 1.30 to 3.26 & 0.002 & - & - & - \\
\hline Neuropathy stage & 0.92 & 0.59 to 1.43 & 0.717 & 0.91 & 0.59 to 1.40 & 0.661 & 0.64 & 0.37 to 1.10 & 0.108 \\
\hline
\end{tabular}

*Mean over time.

†ECG 1, ECG diagnostic of acute myocardial infarction or evolving diagnostic; ECG 2, ECG with left bundle branch block or electronically paced complexes. Significant values in bold.

CASS, composite autonomic severity score; Cl, confidence interval; FPG, fasting plasma glucose; Hb, haemoglobin; HDLC, high density lipoprotein cholesterol; HR, hazard ratio; JTc, corrected JT interval; QTc, corrected QT interval; RDNS, Rochester diabetic neuropathy study. 
differences in the severity of diabetic retinopathy, polyneuropathy, and nephropathy among the groups-notably the stage of nephropathy was more severe in the two groups who died (table 1).

\section{Life table analysis of risk factors for sudden cardiac death}

In univariate analysis, many risk covariates were statistically associated with sudden cardiac death (table 2). The relative hazard for sudden cardiac death associated with each risk factor is shown in table 2. Since the increase in hazard depends on the amount of increase in the corresponding risk factor, we have indicated the increase in risk associated with a clinically meaningful increase in the risk factor. For example, a $1000 \mathrm{mg} / 24$ hour increase in 24 hour microalbuminuria is estimated to result in a 2.38 -fold increased risk of sudden cardiac death. The largest relative hazards were observed for the three ECG variables and calcification of vessels in the foot. In bivariate analysis of risk covariates (table 3), ECG 1 (evolving and previous myocardial infarction), ECG 2 (bundle branch block or electronic pacing), ECG 1 or ECG 2, and nephropathy stage were significant risk factors. Adjusting for ECG 1 or ECG 2, the following factors were significant: CASS total, CASS adrenergic, CASS cardiovagal, QTc interval, HDL cholesterol, 24 hour microalbuminuria, and 24 hour total proteinuria. However, after adjusting for nephropathy stage, none of the autonomic scores, QTc interval, HDL cholesterol, microalbuminuria, or total proteinuria was significant.

\section{Review of death certificates, medical records, and necropsy reports}

All patients who died suddenly had either severe coronary atherosclerosis with myocardial damage at necropsy, or a clinical history of atherosclerosis with clinical left ventricular dysfunction, or both. Unexpected death from arrhythmia had not occurred in the absence of severe coronary atherosclerosis or left ventricular impairment.

\section{DISCUSSION}

The present study provides two lines of evidence that sudden cardiac death relates more directly to coronary ischaemia, cardiac arrhythmia, or nephropathy than it does to diabetic autonomic neuropathy. Based on bivariate life table analysis, ECG evidence of evolving or past myocardial infarction, bundle branch block, and stage of nephropathy were stronger risk covariates than were indicators of autonomic neuropathy or HDL cholesterol. In fact, in bivariate analysis and adjusting for nephropathy stage, autonomic test results were not statistically significant factors. Second, our survey of death certificates, medical records, and necropsy reports revealed evidence of preceding severe atherosclerosis and myocardial damage in all patients dying suddenly. The latter changes were judged to be sufficiently advanced to be the direct cause of death. In other words, cardiac autonomic neuropathy in the absence of severe atherosclerosis or myocardial damage was not found to be associated with sudden cardiac death.

In the light of our results, the role of autonomic neuropathy as the pivotal event in sudden cardiac death in diabetic patients probably needs revision. Ewing et al ${ }^{3}$ first reported an association between DAN and sudden cardiac death. These investigators suggested that autonomic neuropathy and an abnormal brain stem mechanism might be involved in sudden cardiac death. Other workers ${ }^{20} 21$ have also noted an increased frequency of sudden unexpected death in patients with DAN. The hypothesised mechanisms of sudden death have included silent myocardial ischaemia and infarction, impaired central control of respiration, reduction in heart rate variability, $22-24$ sympathovagal imbalance, and predisposition to cardiac arrhythmias because of alterations in the QTC interval. ${ }^{25-28}$ However, actual studies of these functional events at death are not available. In addition, we have also analysed the possible association of the increase in the QTC and JTc intervals with sudden cardiac death. The QTc interval was statistically significant in univariate analysis but like many other putative risk factors this association was not supported in the multivariate life table analysis. Crow and colleagues reported that the JTc interval was a significant independent predictor of incident coronary heart disease in men. ${ }^{29}$ In our study, the JTc interval was not a significant factor associated with sudden cardiac death.

Previous studies suggesting that DAN causes sudden cardiac death have not been sufficiently rigorous. Jouven and colleagues ${ }^{30}{ }^{31}$ studied the risk factors associated with sudden death in a large cohort of patients followed for more than 20 years (Paris prospective study I). They identified parental involvement in sudden death as an independent risk factor. In addition, they found an association between diabetes mellitus and sudden cardiac death after adjusting for other cardiovascular risk factors, but no measurement of autonomic neuropathy was actually undertaken. Other investigators $^{22}$ postulated an alteration in the parasympatheticsympathetic balance in which a reduction in parasympathetic (vagal) tone secondary to DAN leads to a relative overactivity of the sympathetic system; this enhanced sympathetic tone may also play a role in nocturnal hypertension, ventricular arrhythmias, and increased risk of cardiovascular events in diabetic and non-diabetic patients. Our data do not conform to this hypothesis, as we found impairment of both cardiovagal and adrenergic responses. In addition, the coexisting coronary atherosclerosis, myocardial injury, and kidney disease appeared to be sufficient to account for sudden cardiac death.

Scintigraphic studies that analyse the sympathetic innervation of the ventricle may help us to understand the complex relations between ischaemic heart disease, DAN, and sudden cardiac death. Cardiac positron emission tomographic (PET) studies after myocardial infarction have shown regional cardiac sympathetic denervation. ${ }^{1}$ Metaiodobenzylguanidine (MIBG) single photon emission computed tomography (SPECT) studies have shown that diabetic patients with poor glycaemic control have greater areas of left ventricular sympathetic denervation..$^{32}$ Stevens et al ${ }^{33}$ carried out cardiac PET studies and found that diabetic patients with mild DAN had only distal left ventricular sympathetic denervation, but patients with severe DAN showed a pattern of distal cardiac sympathetic denervation associated with proximal ventricular islands of hyperinnervation. These proximal areas also had significant impairment of blood flow. ${ }^{34}$ These areas of denervation and hyperinnervation may cause unstable regions of electrical, vascular, or autonomic heterogeneity conducive to lethal ventricular arrhythmias. ${ }^{35}$ These findings may explain the cardioprotective benefits of $\beta$ blockers and amiodarone-drugs that stabilise autonomic balance-in reducing sudden cardiac death after myocardial infarction. ${ }^{36}$ Although we did not carry out cardiac PET studies in our patients, our findings complement these observations.

Nephropathy was an independent risk factor for sudden cardiac death in our study. In the sudden cardiac death group of our cohort, $31 \%$ of patients had nephropathy stages 3 and 4. Previous studies ${ }^{37} 38$ have documented the increased mortality of diabetic patients with renal failure. Mogensen ${ }^{39}$ reported that the presence of microalbuminuria in patients with diabetes mellitus type II was a predictor of clinical proteinuria and increased mortality. Other studies ${ }^{40}$ have also shown that microalbuminuria is a strong independent risk factor for cardiovascular disease in diabetic and non-diabetic 
individuals, and may be a useful marker of diffuse endothelial dysfunction. The data presented here support this observation. We suggest that nephropathy is not the cause of sudden cardiac death but rather a marker of generalised vascular dysfunction, which, in conjunction with other risk factors, contributes to the causal process.

Our study had limitations. First, serial data obtained before and during sudden cardiac deaths (for example, from an ECG or implanted cardiac recording device) were not available on our patients. Second, we may not have modelled for all applicable risk factors-for example, a family history of sudden cardiac death and the presence of inflammatory markers ( $C$ reactive protein) may be important. Third, the study sample was predominantly of northern European extraction and the results may not apply to other ethnic groups.

\section{Conclusions}

Our findings suggest that coronary artery disease causing ischaemia and renal disease are the main risk factors for sudden cardiac death in the Rochester diabetic neuropathy study cohort. It is possible that DAN may act as the transient factor conducive to the final event, but further studies are necessary to determine this.

\section{ACKNOWLEDGEMENTS}

Supported in part by NINDS 36797 and Mayo Foundation. Presented in part at the 53rd Annual Meeting of the American Academy of Neurology, Philadelphia, PA, May 2001 and 14th International Symposium on the Autonomic Nervous System, St Thomas, US Virgin Islands, November 2003.

\section{Authors' affiliations}

G A Suarez, V M Clark, J E Norell, P A Low, P J Dyck, Peripheral Neuropathy Research Laboratory, Mayo Clinic College of Medicine and Mayo Foundation, Rochester, Minnesota, USA

T E Kottke, M J Callahan, Division of Cardiovascular Disease and Internal Medicine, Mayo Clinic College of Medicine and Mayo Foundation

P C O’Brien, Division of Biostatistics, Mayo Clinic College of Medicine and Mayo Foundation

Competing interests: none declared

\section{REFERENCES}

1 Zipes DP, Wellens HJJ. Sudden cardiac death. Circulation 1998;98:2334-51

2 Anonymous. State-specific mortality from sudden cardiac death - United States, 1999. MMWR 2002:51:123-6.

3 Ewing DJ, Campbell IW, Clarke BF. The natural history of diabetic autonomic neuropathy. Q J Med 1980 Winter;49:95-108.

4 Rathmann W, Ziegler D, Jahnke $M$, et al. Mortality in diabetic patients with cardiovascular autonomic neuropathy. Diabet Med 1993;10:820-4.

5 Sampson MJ, Wilson S, Karagiannis P, et al. Progression of diabetic autonomic neuropathy over a decade in insulin-dependent diabetics. $Q J$ Med 1990;75:635-45.

6 Ewing DJ, Campbell IW, Clarke BF. Mortality in diabetic autonomic neuropathy. Lancet 1976;i:601-3.

7 Dyck PJ, Kratz KM, Lehman KA, et al. The Rochester Diabetic Neuropathy Study: design, criteria for types of neuropathy, selection bias, and reproducibility of neuropathic tests. Neurology 1991;41:799-807.

8 Dyck PJ, Kratz KM, Karnes JL, et al. The prevalence by staged severity of various types of diabetic neuropathy, retinopathy, and nephropathy in a population-based cohort: the Rochester Diabetic Neuropathy Study. Neurology 1993;43:817-24.

9 Dyck PJ, Karnes JL, O'Brien PC, et al. The Rochester Diabetic Neuropathy Study: reassessment of tests and criteria for diagnosis and staged severity. Neurology 1992;42:1164-70.

10 Dyck PJ, Davies JL, Litchy WJ, et al. Longitudinal assessment of diabetic polyneuropathy using a composite score in the Rochester Diabetic Neuropathy Study cohort. Neurology 1997;49:229-39.

11 Dyck PJ, Davies JL, Wilson DM, et al. Risk factors for severity of diabetic polyneuropathy. Intensive longitudinal assessment of the Rochester Diabetic Neuropathy Study cohort. Diabetes Care 1999;22:1479-86.
12 Dyck PJ, Litchy WJ, Lehman KA, et al. Variables influencing neuropathic endpoints: the Rochester Diabetic Neuropathy Study of healthy subjects (RDNS-HS). Neurology 1995;45:1115-21.

13 O'Brien PC, Dyck PJ. Procedures for setting normal values. Neurology 1995:45:17-23.

14 Dyck PJB, Dyck PJ. Diabetic polyneuropathy. In: Dyck PJ, Thomas PK, eds. Diabetic neuropathy. Philadelphia: WB Saunders, 1999:255-78.

15 Dyck PJ, O'Brien PC, Litchy WJ, et al. Use of percentiles and normal deviates to express nerve conduction and other test abnormalities. Muscle Nerve 2001;24:307-10.

16 Low PA. Composite autonomic scoring scale for laboratory quantification of generalized autonomic failure. Mayo Clin Proc 1993;68:748-52.

17 Low PA. Laboratory evaluation of autonomic function. In: Low PA, ed. Clinical autonomic disorders, 2nd ed. Philadelphia: Lippincott-Raven, 1997:179-208

18 Nkomo VT, Kottke TE, Brekke MJ, et al. The ability of a computer program based on the Marquette Matrix-12 short measurement matrix to replicate coding by the Minnesota ECG coding laboratory. J Electrocardiol 2000;33:341-8.

19 Fisher LD, Lin DY: Time-dependent covariates in the Cox proportional-hazards regression model. Annu Rev Public Health 1999;20:145-57.

20 Navarro X, Kennedy WR, Lowenson RB, et al. Influence of pancreas transplantation on cardiorespiratory reflexes, nerve conduction and mortality in diabetes mellitus. Diabetes 1990;39:802-6.

21 O'Brien IA, McFadden JP, Corrall RJM. The influence of autonomic neuropathy on mortality in insulin-dependent diabetes. Q J Med 1991;79:495-502.

22 Weston PJ, Gill GV. Is undetected autonomic dysfunction responsible for sudden death in type 1 diabetes mellitus? The "dead in bed" syndrome revisited. Dibet Med 1999; 16:626-31.

23 McNally PG, Lawrence IG, Panerai RB, et al. Sudden death in type 1 diabetes. Diabetes Obes Metab 1999;1:151-8.

24 Harris ND, Heller SR. Sudden death in young patients with type 1 diabetes: a consequence of disease, treatment or both? Diabet Med 1999;16:623-5.

25 Montanez A, Ruskin JN, Hebert PR, et al. Prolonged QTc interval and risks of total and cardiovascular mortality and sudden death in general population: a review and qualitative overview of the prospective cohort studies. Arch Intern Med 2004; 164:943-8.

26 Sivieri R, Veglio M, Chinaglia A, et al. Prevalence of QT prolongation in a type 1 diabetic population and its association with autonomic neuropathy. The Neuropathy Study Group of the Italian Society for the Study of Diabetes. Debet Med 1993;10:920-4

27 Ewing DJ, Boland O, Neilson JM, et al. Autonomic neuropathy, QT interval lengthening, and unexpected deaths in male diabetic patients. Diabetologia 1991;34:182-5.

28 Bellavere F, Ferri M, Guarini L, et al. Prolonged QT period in diabetic autonomic neuropathy: a possible role in sudden cardiac death? $\mathrm{Br}$ Heart $J$ 1988; J59:379-383.

29 Crow RS, Hannan PJ, Folsom AR. Prognostic significance of corrected QT and corrected JT interval for incident coronary heart disease in a general population sample stratified by presence or absence of wide QRS complex: the ARIC Study with 13 years of follow-up. Circulation 2003;108:1985-9.

30 Jouven X, Desnos M, Guerot C, et al. Predicting Sudden Death in the Population. The Paris Prospective Study I. Circulation 1999;99:1978-83

31 Balkau B, Jouven X, Ducimetiere P, et al. Diabetes as a risk factor for sudden death. Lancet 1999;354:1968-9.

32 Ziegler D, Weise F, Langen KJ, et al. Effect of glycaemic control on myocardial sympathetic innervation assessed by $\left[{ }^{123} \mathrm{I}\right]$ metaiodobenzylguanidine scintigraphy: a 4-year prospective study in IDDM patients. Diabetologia 1998;41:443-51

33 Stevens MJ, Raffel DM, Allman KC, et al. Regression and progression of cardiac sympathetic dysinnervation complicating diabetes: an assessment by C-11 hydroxyephedrine and positron emission tomography. Metabolism 1999;48:92-101

34 Stevens MJ, Dayanikli F, Raffel DM, et al. Scintigraphic assessment of regionalized defects in myocardial sympathetic innervation and blood flow regulation in diabetic patients with autonomic neuropathy. J Am Coll Cardiol regulation in diabe

35 Stevens MJ, Raffel DM, Allman KC, et al. Cardiac sympathetic dysinnervation in diabetes: implications for enhanced cardiovascular risk. Circulation 1998;98:961-8.

36 Effect of prophylactic amiodarone on mortality after acute myocardial infarction and in congestive heart failure: meta-analysis of individual data from 6500 patients in randomised trials. Amiodarone Trials Meta-Analysis Investigators. Lancet 1997;350:1417-24.

37 Dinneen SF, Gerstein HC. The association of microalbuminuria and mortality in non-insulin- dependent diabetes mellitus. A systematic overview of the literature. Arch Intern Med 1997;157:1413-18.

38 Wilson DM. Diabetic nephropathy. In: Dyck PJ, Thomas PK, eds. Diabetic neuropathy. Philadelphia: WB Saunders, 1999:67-82.

39 Mogensen CE. Microalbuminuria predicts clinical proteinuria and early mortality in maturity-onset diabetes. N Engl J Med 1984;310:356-60.

40 Gerstein HC, Mann JF, Yi Q, et al. Albuminuria and risk of cardiovascular events, death, and heart failure in diabetic and nondiabetic individuals. JAMA $2001 ; 286: 421-6$ 